Yergiyev I. On the problem of typology of artistic performance styles. In the article the problem of «performance style» definition in its artistic performance is actualized. It's made the attempt of specific typology of artistic performance styles in terms of the psychology of actor's thinking, which is typical for post-neoclassical artistic method. The latter shows itself in «live» intonation of instrumentalists' creativity that objectifies their performing interpretation in the system of visual expression and scenic art technology. The methodological basis for solving this problem was in such theories as the concept of world-view, historical musical styles, socionics and communication.

Key words: artistic performance style, creative work, interpretation, musical style, musical thinking, world-view.

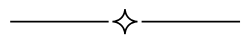

УДК 78.03(477.61)

О. Оганезова-Григоренко

\title{
СОЦИОКУЛЬТУРНЫЕ АСПЕКТЫ ФОРМИРОВАНИЯ ПРОФЕССИОНАЛИЗМА АРТИСТА МЮЗИКЛА
}

Статья посвящена проблеме специфики профессионального мастерства артиста мюзикла в его социокультурном аспекте. Мюзикл рассматривается как феномен не только театральной, но и так называемой массовой культуры. Рассматриваются социально-культурные факторы, которые от истоков становления жанра мюзикла влияли на особенности формирования специфического типа профессионализма артиста мюзикла, обусловленного, с одной стороны, триединой природой жанра - органичный сплав вокала, таниа, драмы, и, с другой, наличием сформированной артистической индивидуальности, чутко реагирующей на социально-культурные факторы современного мира и музыкального искусства.

Ключевые слова: мюзикл, артист, профессионализм, социокультурный фактор, синтез.

Мюзикл является одним из самых популярных жанров музыкально-драматического искусства, который получил широкое распространение в современной культуре. В силу своей «упрощенности», доступности и зрелищности (в сравнении с оперным искусством) этот жанр музыкального театра пользуется спросом у современного слушателя самых разных возрастных категорий и степени музыкальной осведомленности. Синтетическая природа мюзикла и доступ- 
ность его музыкального языка обеспечивает очень высокий уровень воздействия на широкого зрителя, который всегда «узнает» в сюжетах и музыкально-драматических образах подобие своей жизненной реальности. Это позволяет рассматривать мюзикл как феномен не только театральной, но и так называемой массовой культуры, которая в различных формах транслирует культурные запросы своего времени и которая формирует определенный тип артистической индивидуальности, чутко реагирующей на социально-культурные факторы современного мира и музыкального искусства.

В этом смысле профессионализм артиста мюзикла представляет собой весьма сложное явление, прежде всего - в силу своей принципиальной комплексности: триединство вокального, хореографического и драматического элементов мастерства, которое должно органично сочетаться с социально-культурной достоверностью создаваемого образа, его современным «звучанием». Соответственно, не раз отмечалось, что «...к артистам мюзикла предъявляются очень высокие и разноплановые требования. Поэтому справедливо считается, что профессионализм в мюзикле - явление уникальное» [5, с. 168].

Поэтому в условиях несомненной популярности мюзикла в современной культуре и социальной востребованностью артистов актуальным является изучение особенностей профессионального облика артиста мюзикла (особенно учитывая то обстоятельство, что в отечественном искусствоведении разработки этой проблемы весьма малочисленны).

Цель статьи - выявление социокультурных аспектов, влияющих на формирование специфического типа профессионализма артиста мюзикла. Объект исследования - профессиональный облик артиста мюзикла. Предмет исследования - влияние социокультурных факторов на формирование специфического типа профессионализма артиста мюзикла. Музыкальный театр во все времена отражал общие культурные процессы, характерные для той или иной эпохи, в музыкально-драматическом искусстве всегда воплощались эстетические, этические, нравственные и социально-ценностные запросы общества, его культурные потребности. Разнообразие этих запросов и потребностей нашло свое воплощение в жанровых вариантах музыкально-драматического искусства, сформировавшихся в мировой театральной традиции, среди которых мюзиклу принадлежит совершенно особая роль. Зародившись в конце XIX столетия как развлекательный жанр, мюзикл со временем превратился в самый крупный и 
показательный жанр массовой культуры. И этот жанр со второй половины прошлого века заявил о себе как о серьезном искусстве, способном говорить о «больших» темах на своем более доступном и простом музыкальном языке, нежели, например, академическое оперное искусство.

В музыковедческой литературе проблемы жанров «легкой музыки» в их социокультурном рассмотрении до сих пор не получили должного освещения. В числе немногих русскоязычных источников необходимо назвать диссертации В. Савранского «Музыкально-жанровая сущность оперетты», А. Сахаровой «Музыкальный театр Эндрю Ллойда Уэббера: жанрово-стилевые модели массовой и академической музыки», А. Сысоевой «Бродвейский мюзикл. Процесс формирования жанра в 10-е - 20-е годы XX века», книгу Т. Кудиновой «От водевиля до мюзикла». В указанных исследованиях объектом изучения является жанрово-стилевой облик мюзикла, в рассмотрении которого лишь косвенно затрагивается социокультурный контекст его эволюции. Дифференциация «массового» и «академического» показателя поэтики мюзиклов Э. Л. Уэббера в диссертации А. Сахаровой проводится в аспекте типов музыкальной выразительности, минуя социокультурные смыслы анализируемых сочинений [8].

«Легкость» и «развлекательность» мюзикла, которые, несомненно, составляют его жанровую специфику, только на первый взгляд являются его определяющими стилевыми качествами. Вся история развития этого жанра в американской и европейской музыкальной культуре говорит о принципиальной сложности поэтики мюзикла. Соответственно, встает вопрос об уникальном в своей многопрофильности исполнительском профессионализме артиста мюзикла. Синтетическая специфика этого жанра музыкально-драматического искусства определила его многоуровневую систему выразительных средств. Каждый из компонентов мюзикла - вокал, танец, сценическое движение, драматическое искусство - обладает своим выразительным и коммуникативным потенциалом, и каждый из них является равноправной возможностью для передачи замысла авторов и создателей спектакля. При этом в разных постановках может превалировать вокальная составляющая (классический и современный мюзикл, рок-опера, поп-опера), в других - танцевальная (дэнсмюзикл), в третьих - драматическая линия (драма-мюзикл). Исполнительское мастерство артиста мюзикла, соответственно, вбирает в себя весь этот комплекс различных выразительных возможностей, 
образуя синтетическую (комплексную) природу профессионализма исполнителя. Исходя из того, что музыкальное искусство является неотъемлемой частью любой культуры, подчиняется законам общественного развития и отражает основные преобразования эпохи, очевидна взаимосвязь социальных потребностей эпохи с конкретными жанровыми особенностями. Такое представление о музыкальном искусстве составило основание музыкальной социологии, которая утверждает, что «жанр, включая в себя социальные, исторические и культурные категории, является... неким «культурным отражателем» эпохи» [6, с. 45].

Однако нельзя отрицать того, что сам тип профессионального мастерства обусловлен социокультурными факторами жанра, в котором он и был сформирован. Жанр мюзикла формировался долго и стихийно, подчиняясь запросам «рынка», отвечая злобе дня, отражая умонастроения и предпочтения массового зрителя, можно сказать, отражая течение и развитие социальной жизни. Чтобы понять специфику мюзикла как социокультурного феномена, обратимся к работе одного из немногочисленных исследователей этого жанра, и рассмотрим истоки мюзикла с точки зрения формирования социокультурного портрета потребителей жанра, а следовательно, и специфики индивидуальности артиста, работающего в этом жанре.

Э. Ю. Кампус в работе «О мюзикле» характеризует такие истоки жанра:

1) балладная опера - комедийно-музыкальное представление, родившееся в XVIII веке в Европе (в Италии - опера-буфф, во Франции - комическая опера, а Англии - балладная опера). Популярные мелодии народного характера сплавились в жанре балладной оперы в своеобразный городской фольклор, один из источников музыкальной эстрады США вплоть до современной поп-культуры [1, с. 23-24]. Стремление балладной оперы к злободневности, к изображению повседневного быта, элементы сатиры - все это в известной мере явилось предвосхищением мюзикла как социально-злободневного жанра;

2) «театр менестрелей» - корни этого искусства берут начало в английской балладной опере и «дроллс». В музыке «театра менестрелей» сформировались некоторые ранние элементы джаза (регтайм). Влившись в бродвейскую эстраду, менестрели способствовали проникновению джаза на профессиональные сценические подмостки $[1$, c. $24-26]$; 
3) экстраваганца - необычные, фантастические представления, полные мелодраматических событий и умопомрачающих сценических эффектов, приправленных песнями и танцами, элементами варьете и цирковыми аттракционами. Экстраваганца положила начало традиции пышных эффектных зрелищ с музыкой, пением и танцами [1, c. 26-29];

4) бурлеск - «травести», пародия на серьезную известную пьесу, где популярные песни и комические номера стали важнее, чем литературный первоисточник. Злободневность сюжетов, узнаваемость персонажей, правдивость диалогов, просторечье, иногда идентичность стриптизу - бурлеск оставил в наследство мюзиклу прежде всего остроту трактовки современных проблем [1, с. 29-31];

5) водевиль - в американском варианте набор эстрадных номеров, что-то вроде современного эстрадного обозрения со сквозным сюжетом. Американский водевиль опирается на английские традиции и является наследником мюзик-холла. Водевиль принуждал к собранности и точности, чего развлекательный театр не знал. Ни одна исполняемая сцена не должна была превышать десяти минут. От водевильной «звезды» требовалось умение играть, танцевать и петь [1, c. 31-34];

6) ревю - конгломерат пародии, сатиры, комических номеров, песен и танцев. Новым являлось не содержание, а способ монтажа отдельных элементов. Ревю и водевиль - близнецы. Оба представляют собой каскад словесных, музыкальных, танцевальных и акробатических номеров, в котором присутствует единое действие, но в ревю имеется тематическое единство. Из ревю в мюзикл перешло умение объединять в едином представлении разнородные, на первый взгляд, несовместимые элементы [1, с. 34-35];

7) оперетта - на всем протяжении своего пути (полвека) американская оперетта подражала европейской. Американская публика видела в ней романтическое и экзотическое действие, далекое от реальности. Потребность в более демократическом, актуальном жанре, тесно связанном с действительностью, породила мюзикл. Он возник не как продолжение, а как отрицание оперетты. Однако это не исключает преемственность между этими жанрами [1, с. 35-41];

8) джаз - синтезировал в себе элементы разных жанров: балладной оперы, «театра менестрелей», экстраваганцы, бурлеска, водевиля, ревю, оперетты. Джазу в этом синтезе принадлежит роль фермента, катализатора [1, с. 41-42]. 
Исследования Кампуса характеризуют не просто музыкальные истоки мюзикла как жанра, а его социальную многогранность - как характеристику огромного спектра «заказчиков» и «потребителей» этого жанра. А если адресат столь многообразен, то исполнитель должен обладать профессиональными умениями и личностными характеристиками такого уровня, который бы позволял ему быть интересным любой зрительской аудитории.

Иными словами, с профессиональной точки зрения актер мюзикла должен быть одинаково убедителен как в комедии, так и в драме, быть убедителен в самом различном вокальном стилевом исполнительском спектре - как в классическом, так и в джазовом, роковом, шансоне, романсе, владеть пластическими приемами самых различных направлений. Кроме того, актер мюзикла (в отличие от оперного артиста) не может не обладать сценическим обаянием и личной харизмой, совпадение внешнего вида и содержательного наполнения персонажа обязательно (в мюзикле, в отличие от оперы, не может Джульетта выглядеть как ее располневшая кормилица).

Рассмотрим теперь социально-ценностные аспекты личности актера мюзикла. Эклектичность мюзикла (имеем в виду широчайший спектр художественных приемов) как нельзя точно характеризует современную социальную среду (современную - имеем в виду XXXXI вв.). Театр не для элиты, а театр для всех - близкий, понятный, охватывающий все способы художественного воздействия на человека. Герой этого жанра не легендарный рыцарь, а мальчишка из толпы («Оливер» Л. Барта), актеры провинциального театра («Целуй меня, Кэт!» К. Портера), жители еврейской деревушки («Скрипач на крыше» Дж. Бока). Позже мюзикл начинает захватывать территории классической драмы - «Отверженные» К. М. Шонберга, мистического триллера - «Призрак оперы» Э.-Л. Уэббера, сказочно-иносказательного мира - «Кошки» Э.-Л. Уэббера.

Но во всем своем многообразии мюзикл лучше и полнее других сценических жанров раскрывает душу героя сегодняшнего мира. «Мюзикл наделяет своего героя психологией, мироощущением, обликом, а также ритмами своего времени», - утверждает Т. Кудинова [2, с. 126]. Герой в мюзикле неизменно современен. Даже если это исторический персонаж, он часто подвергается ироничной модернизации («Иисус Христос - суперзвезда» Э.-Л. Уэббера, «Граф Воронцов» Е. Ульяновского, «Экватор» А. Злотника). Признанный мэтр музыкального театра И. А. Гриншпун утверждал, что «для актера в 
музыкальном театре чувство юмора - условие обязательное. А юмор всегда связан с находчивостью» [7, с. 34]. Чувства и желания героя мюзикла понятны современному социуму. Это не интеллектуал, сегодняшний герой не рефлексирует, он выбирает инстинктивно, реагирует на обстоятельства быстро, на подсознательном уровне. Герой нашего времени - это не рассуждающий Печорин, это влюбленные Тони и Мари («Вестсайдская история» Л. Бернстайна) - современное воплощение Ромео и Джульетты. «Архетипность» современного героя ближе установкам и мотивациям первобытных порывов, интуитивного, а не интеллектуального контакта с Миром. Герой узнаваем, похож на каждого и не на кого-то конкретно, потому что черты его присущи любому современному представителю глобального, перегруженного информацией пространства. На наш взгляд, ведущая роль музыки и ритма в мюзикле точно иллюстрирует эту особенность восприятия современного зрителя - не интеллект, а чувство, рефлекс, порыв, то, что подчас нельзя сформулировать словами.

Изначально различные формы музыкального театра, определившие жанровую специфику американского мюзикла, имели четкую социально-культурную идею: они должны были отвлечь зрителя-слушателя от трудностей повседневной реальной жизни, служить некоей отдушиной, которая позволяла «переключиться» из мира забот в мир прекрасного, привлекательного и беззаботного. Соответственно, рядовому зрителю должно быть интересно, понятно и весело. По этому поводу исследователь А. В. Сахарова отмечает: «Мюзикл как явление, принадлежащее в значительной степени сфере массовой культуры, потребовал привлечения музыкально-социологических, психологических и культурологических методов исследования» [8, с. 3]. Эта специфическая особенность мюзикла составила его генетическую идею - как жанра развлекательной и «легкой» музыкальной культуры. Некоторые исследователи театрального искусства отмечают, что часто «...установка на «развлекательность» сопровождается понижением оценки актерской игры...» [9, с. 141-142].

Однако в отношении мюзикла это утверждение представляется спорным. Именно в этом жанре музыкально-драматического искусства актерская игра в комплексе с вокальным и хореографическим элементами служит воплощению запросов современника, что составляет основную художественную идею жанра. (Впору вспомнить тезис В. И. Ленина: «Искусство принадлежит народу и должно быть понято им».) В данном случае культурные запросы общества (в узком смыс- 
ле - публики) в развлекательном и доступном для рядового восприятия искусстве не упрощают, но усложняют профессиональный облик артиста. Смысл исполнительского мастерства артиста мюзикла как раз и заключается в том, что он должен уметь все - петь, танцевать, играть. И с помощью этих художественных средств «вдыхать» жизнь в самые разные истории, отображающие в разных аспектах жизнь социума. Это может быть бытовая история - «Скрипач на крыше» Дж. Бока или «Безымянная звезда» М. Самойлова, комедия - «Хелло, Долли!» Дж. Хермана или «Дон Сезар де Базан» Е. Ульяновского, социальная драма - «Кабаре» Дж. Кендера или «Гадюка» А. Колкера, трагедия - «Мисс Сайгон» К.-М. Шонберга или «Белая ворона» Г. Татарченко, волшебная сказка - «Призрак оперы» Э.-Л. Уэббера или «Обыкновенное чудо» Г. Гладкова.

Можно сделать вывод о том, что формирование типа артистического профессионализма, характерного для мюзикла, напрямую зависит от социокультурных факторов. Под социокультурными факторами обычно принято понимать преобладающие в обществе жизненные ценности, нравственно-этические установки, эстетические идеалы (прямо производные от этических ценностей), культурные традиции. По мнению В. С. Мерлина, социальные условия влияют на все иерархические уровни свойств человека, и индивидуальность всегда соотнесена с социокультурной средой [4, с. 29]. В процессе формирования творческой индивидуальности, на наш взгляд, стимулятором процесса является именно социальный фактор. Искусство артиста социально по своей природе. Если художник, писатель, композитор могут «работать в стол», то артисты - исполнители всегда нуждаются в социальной оценке «здесь и сейчас». Личность артиста, с одной стороны, требует самовыражения, с другой - испытывает внешнее воздействие социально-культурной среды (в лице зрителя, заказчика, оценщика качества профессиональной работы). Взаимодействие художественной личности актера и общества, в более узком смысле - публики, развивается в рамках синергетической парадигмы: «организм и окружающая среда связаны процессуальным единством и представляют собой систему» Э. Ласицкая [3, с. 16].

В этой системе обоюдно реализуются потребности как артиста, так и публики: с одной стороны, личностный, индивидуальный запрос артиста в творческом самовыражении (самоактуализации), с другой - эстетические и аксиологические потребности публики, 
«требующие» от театра и артиста их художественного опредмечивания. Мы рассматриваем актера мюзикла как творческую артистическую индивидуальность. Исторически в анализе индивидуальности сложились два подхода: антропоцентрический - взгляд «изнутри», через экзистенциальное бытие человека; социоцентрический - обусловленный влиянием социальных детерминант. При оценке зрелой творческой артистической индивидуальности, на наш взгляд, антропоцентрический подход к оценке преобладает над социоцентрическим, т. к. зрелый артист уже более сам влияет на социум, чем находится под его влиянием.

Bыводы. Очевиден тот факт, что формирование профессионализма артиста мюзикла неразрывно связано с социокультурными факторами. Эта взаимосвязь культурных запросов общества и жанровой специфики мюзикла была заложена в самом начале истории этого жанра, выдвинувшего уникальный комплексный тип профессионализма (в рамках «легкого» жанра!). Все приобретенные профессиональные навыки и знания артиста мюзикла «опредмечиваются» в создаваемом им образе, переходят в конкретный предмет деятельности, воплощаются в нем, благодаря чему деятельность становится социальнокультурной. Психофизиологический аппарат исполнителя в процессе формирования и профессиональной эксплуатации всегда взаимодействует с осмыслением и пониманием социальных, этических и эстетических факторов артистической деятельности. Следствие слияния этих аспектов - профессионал с выраженной позицией художника, которая проявляется не только на уровне технологически качественной работы в профессии, но и на уровне выбора, трактовки, смыслового и морального наполнения сценического материала.

\section{СПИСОК ЛИТЕРАТУРЫ}

1. Кампус Э. О мюзикле / Э. Кампус. - Л. : Музыка, 1983. - 128 с.

2. Кудинова Т. От водевиля до мюзикла/ Т. Кудинова. - М. : Сов. композитор, 1982. $-175 \mathrm{c}$.

3. Ласицкая Э. В. Концепция автопоэзиса: бытие, познание, деятельность / Э. В. Ласицкая // Известия Саратовского университета. - 2011. - Т. II, Вып. 4. - С. 14-16. - (Серия: Философия. Психология. Педагогика).

4. Мерлин В. С. Психология индивидуальности / В. С. Мерлин ; [под ред. Е. А. Климова]. - М. : Институт практической психологии ; Воронеж : НПО «МОДЭК», 1996. - $448 \mathrm{c}$.

5. Монд О. Условия и факторы вершинных достижений исполнителей мюзикла / О. Монд // Проблемы и перспективы развития образования : ма- 
териалы Междунар. науч. конф. (г. Пермь, апрель 2011 г.). - Пермь : Меркурий, 2011. - Т. 2. - С. 168-171.

6. Носова И. П. К проблеме влияния социокультурных аспектов на эволюцию музыкального жанра (на примере этюда) / И. П. Носова // Вестник Томского государственного университета. - 2007. - № 303. - С. 45-48.

7. О музыкальном воспитании актера в театральном вузе : сб. науч. тр. / Ленингр. гос. ин-т театра, музыки и кинематографии им. Н. К. Черкасова ; [редкол. : Н. Н. Алексеев (отв.ред.) и др.]. - Л. : ЛГИТМИК, 1987. - 142 с.

8. Сахарова А. В. Музыкальный театр Эндрю Ллойда Уэббера: жанровостилевые модели массовой и академической музыки : дис. ... канд. искусст. : 17.00.02. - Музыкальное искусство / А. В. Сахарова. - Москва, 2008. - 249 с.

9. Театр и публика : Опыт социологического исследования 1960-1970 годов / отв. ред. В. Н. Дмитриевский. - М. : Государственный институт искусствознания, «Канон +», РООИ «Реабилитация», 2013. - 400 с. - (Социология и экономика искусства : научное наследие).

Оганезова-Григоренко О. Соціокультурні аспекти формування професіоналізму артиста мюзиклу. Стаття присвячена проблемі специфіки професійної майстерності артиста мюзиклу в його соціокультурному аспекті. Мюзикл розглядається як феномен не лише театральної, а й так званої масової культури. Розглядаються соціально-культурні чинники, які від витоків становлення жанру мюзиклу впливали на особливості формування специфічного типу професіоналізму артиста мюзиклу, обумовленого, з одного боку, триєдиною природою жанру - органічного сплаву вокалу, танцю, драми, та, з іншого боку, наявністю сформованої артистичної індивідуальності, яка чутливо реагує на соціально-культурні фактори сучасного світу та музичного мистецтва.

Ключові слова: мюзикл, артист, професіоналізм, соціокультурний чинник, синтез.

Oganezova-Grigorenko $O$. The sociocultural aspects of forming of professionalism of artist of musical. Article is devoted to a problem of specifics of professional skill of the actor of the musical in its social and cultural aspect.The musical is considered as a phenomenon not only theatrical, but also so-called mass culture. Welfare factors which from sources of formation of a genre of the musical influenced features of formation of specific type of professionalism of the actor of the musical caused, on the one hand, by the triune nature of a genre - an organic alloy of a vocal, dance, the drama, and, with another, existence of the created artistic identity which is sensitively reacting to welfare factors of the modern world and musical art are considered.

Key words: musical, actor, professionalism, social and cultural factor, synthesis.

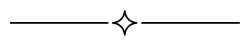

